\title{
Identifying flowlines and limitations of flux analyses in the interior of Thwaites Glacier, Antarctica
}

\author{
T.J. FUDGE, ${ }^{1}$ H. CONWAY, ${ }^{1}$ G. CATANIA, ${ }^{2}$ D.D. BLANKENSHIP, ${ }^{2}$ K. CHRISTIANSON, ${ }^{3}$ \\ I. JOUGHIN, ${ }^{4}$ B. SMITH, ${ }^{4}$ S.D. KEMPF, ${ }^{2}$ D.A. YOUNG, ${ }^{2}$ S. ANANDAKRISHNAN ${ }^{5}$ \\ ${ }^{1}$ Department of Earth and Space Sciences, University of Washington, Seattle, WA, USA \\ E-mail: tjfudge@u.washington.edu \\ ${ }^{2}$ Institute for Geophysics, University of Texas at Austin, Austin, TX, USA \\ ${ }^{3}$ St Olaf College, Northfield, MN, USA \\ ${ }^{4}$ Applied Physics Laboratory, University of Washington, Seattle, WA, USA \\ ${ }^{5}$ Department of Geosciences, The Pennsylvania State University, University Park, PA, USA
}

\begin{abstract}
Patterns in radar-detected internal layers in glaciers and ice streams can be tracked hundreds of kilometers downstream. We use distinctive patterns to delineate flowbands of Thwaites Glacier in the Amundsen Sea sector of West Antarctica. Flowbands contain information for the past century to millennium, the approximate time for ice to flow through the study region. GPS-detected flow directions (acquired in 2007/08) agree within uncertainty $\left(\sim 4^{\circ}\right)$ with the radar-detected flowlines, indicating that the flow direction has not changed significantly in recent centuries. In contrast, InSARdetected directions (from 1996) differ from the radar- and GPS-detected flowlines in all but the middle tributary, indicating caution is needed when using InSAR velocities to define flow directions. There is agreement between all three datasets in the middle tributary. We use two radar-detected flowlines to define a $95 \mathrm{~km}$ long flowband and perform a flux balance analysis using InSAR-derived velocities, radardetected ice thickness, and estimates of the accumulation rate. Inferred thinning of $0.49 \pm 0.34 \mathrm{~m} \mathrm{a}^{-1}$ is consistent with satellite altimetry measurements, but has higher uncertainty due mainly to the velocity uncertainty. The uncertainty is underestimated because InSAR velocities often differ from GPS velocities by more than the stated uncertainties.
\end{abstract}

KEYWORDS: Antarctic glaciology, glacier flow, radio-echo sounding

\section{INTRODUCTION}

Thwaites Glacier in the Amundsen Sea sector of West Antarctica has an area of $\sim 182000 \mathrm{~km}^{2}$, and much of it is grounded well below sea level with an inward-sloping bed (Holt and others, 2006). The catchment consists of tributaries that merge into the main trunk (Fig. 1). The glacier is currently losing mass at a rate of $\sim 20 \mathrm{Gt} \mathrm{a}^{-1}$ (Rignot and others, 2008); thinning is $4 \mathrm{~m} \mathrm{a}^{-1}$ in fast-moving regions near the grounding line, decreasing to $0.1 \mathrm{~m} \mathrm{a}^{-1}$ in slowermoving $\left(<100 \mathrm{~m} \mathrm{a}^{-1}\right)$ regions farther inland (Pritchard and others, 2012). Changes over the past three decades include acceleration (Rignot and others, 2002), increased thinning (Pritchard and others, 2009; Shepherd and others, 2012), loss of ice-shelf buttressing (MacGregor and others, 2012) and increased ocean warming (Pritchard and others, 2012). Accumulation in the catchment has changed little over past decades (Medley and others, 2013).

Over the past two decades, Thwaites Glacier has not accelerated as dramatically as Pine Island Glacier, but has increased its rate of mass loss due to widening of the fastflow region, particularly on the eastern margin (Rignot, 2008). The eastern margin is not well constrained by topography or basal properties and may be susceptible to migration (MacGregor and others, 2013). Inferring changes in flow pattern is difficult because observations in the upper regions of Thwaites Glacier span only a few decades; other indicators used for inferring past flow directions, such as flow stripes (Fahnestock and others, 2000) or crevassing at shear margins (Shabtaie and others, 1988), are not visible on Thwaites Glacier. Radar-detected internal layers can be used to extract information about past ice flow over century timescales; here we adapt methods developed by $\mathrm{Ng}$ and Conway (2004). The radar-detected layers in fast-flowing ice often show trough-and-crest sequences that are inherited from flow disturbances farther upstream. Although the origin of the layer patterns is often not known, the patterns can be used to define the geometry of past flowbands by tracking sequences between radar profiles perpendicular to the ice flow.

Quantifying the amount of thinning in the interior of Thwaites Glacier helps constrain the rate at which perturbations at the grounding line propagate inland (Payne and others, 2004; Joughin and others, 2010a). For the fastflowing region approximately $100-200 \mathrm{~km}$ inland of the grounding line, satellite radar altimetry indicates thinning of $\sim 0.10 \mathrm{~m} \mathrm{a}^{-1}$ for $1992-2003$ with an uncertainty of $\sim 0.1 \mathrm{~m} \mathrm{a}^{-1}$ (e.g. Zwally and others, 2005; Helsen and others, 2008). Satellite laser altimetry suggests slightly greater thinning of $\sim 0.15 \pm 0.07 \mathrm{~m} \mathrm{a}^{-1}$ (Pritchard and others, 2009) for 2003-09. Altimetry measurements are sensitive to interannual variations in accumulation rate and changes in firn compaction. Flux analysis of flowbands is a potential complementary method for determining inland thinning rates because it is not sensitive to interannual accumulation variability. Shabatie and others (1988) used flux analyses to assess the mass balance of Mercer, Whillans and Kamb ice streams on the Siple Coast. They found a similar spatial pattern of thinning and thickening to that found by flux analysis using satellite measurements of velocity (Joughin and others, 2002; Pritchard and others, 2009). 


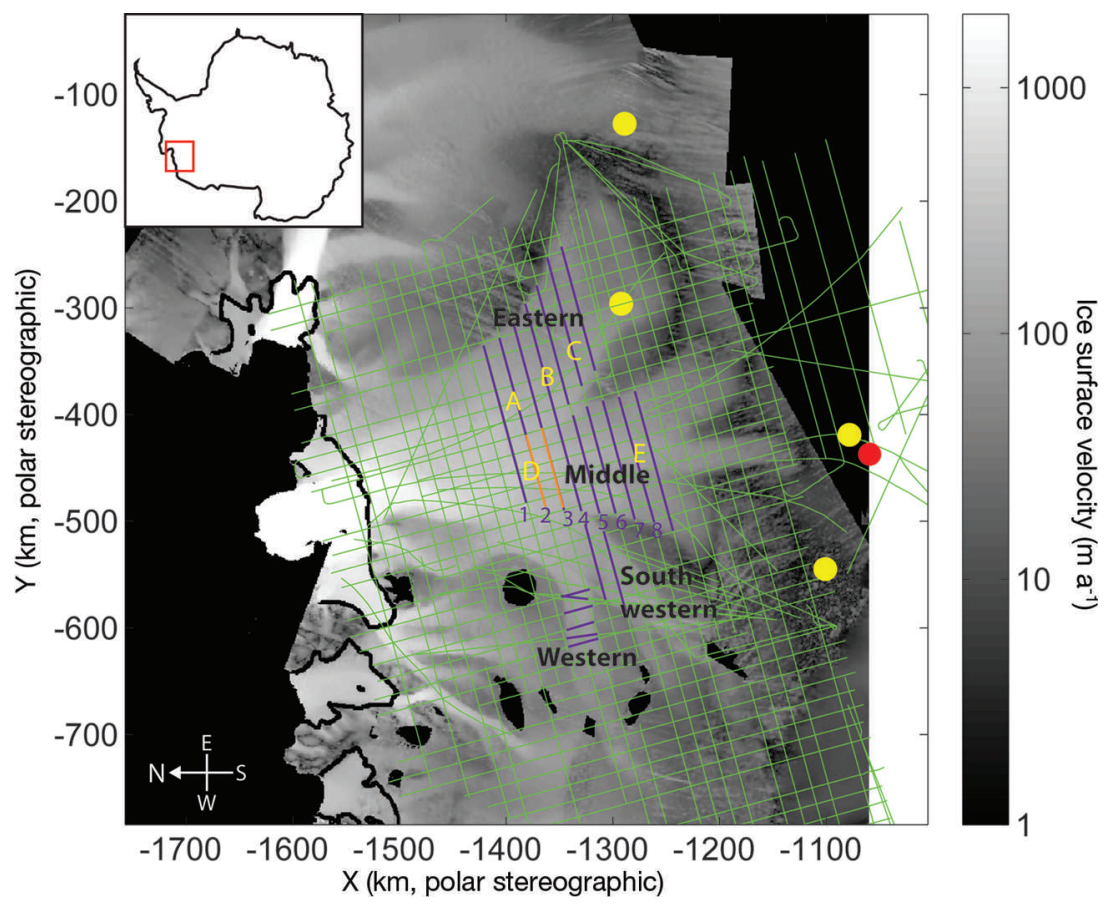

Fig. 1. InSAR velocity map (Joughin and others, 2009) overlain by radar lines (Holt and others, 2006). Green lines are radar lines collected in the AGASEA (Airborne Geophysical Survey of the Amundsen Sea Embayment, Antarctica) campaign. Purple and orange lines indicate areas where radar-detected features were tracked; orange lines are shown in Figure 2. The numbers indicate radar lines L1-L8. Yellow circles are shallow core locations from the United States International Trans-Antarctic Scientific Expedition. Red circle is the West Antarctic Ice Sheet Divide icecore site. A-E are GPS locations. Bold black line is approximate grounding line position. Inset map shows study location.

\section{DATA SOURCES AND METHODS}

\subsection{Radar-detected ice thickness and internal layers}

Airborne geophysical surveys of the Amundsen Sea Embayment by the University of Texas Institute for Geophysics (UTIG) and the British Antarctic Survey provide measurements of ice thickness (Holt and others, 2006; Vaughan and others, 2006; Blankenship and others, 2012) and internal layering. We use radar data collected by UTIG with a $60 \mathrm{MHz}$, phase-coherent High-Capability Radar Sounder (HiCARS) system (Peters and others, 2005) that were rangemigrated using along-track synthetic aperture radar (SAR) focusing (Peters and others, 2007). Ice thickness was mapped along radar profiles that were collected on $15.6 \mathrm{~km}$ grids over Thwaites Glacier (Fig. 1). Radar-detected internal layers were picked and mapped using a seismic package (Geoframe) with strong crossover control. The conversion of radar travel times to depth assumed a constant wave velocity of $168.374 \mu \mathrm{s} \mathrm{m}^{-1}$ and did not incorporate a firn layer (Holt and others, 2006).

\subsection{Radar-detected flowlines}

We mapped past flowlines through the study region by tracking positions of recognizable features (crest and trough sequences) between successive pairs of radar cross-profiles (Fig. 2). Positions of recognizable features were picked independently; that is, when picking features between crossprofiles L2 and L3, the positions of picks between crossprofiles L1 and L2 were not considered. A total of 191 flowlines were tracked (Fig. 3; Conway and others, 2010); most were located in the eastern and middle tributaries. Fewer flowlines could be tracked in the western tributaries because the radar profiles often crossed the flow direction at angles greater than $30^{\circ}$. Four flowlines in the middle tributary could be tracked over $110 \mathrm{~km}$ through eight cross-profiles.
Uncertainty in the flowlines was estimated from the differences between picks of a feature at each radar line. Features were on average identified within $140 \mathrm{~m}$, with a maximum difference of $380 \mathrm{~m}$. This results in a $\sim 3^{\circ}$ uncertainty in the direction of a flowline. The radar-detected layers provide information on timescales related to the advection of ice between upstream and downstream crossprofiles ( $\mathrm{Ng}$ and Conway, 2004). The velocities range from 75 to $400 \mathrm{~m} \mathrm{a}^{-1}$ in the study area, so the time for flow through the study area ranges from $\sim 50$ years for a feature identified in one pair of radar profiles $(\sim 15.6 \mathrm{~km})$ to $\sim 600$ years for features tracked through eight radar profiles $(\sim 110 \mathrm{~km})$.

\subsection{Satellite-derived velocity field}

We use a map of 1996 surface velocities derived using interferometric SAR (InSAR) and speckle-tracking methods (Joughin and others, 2009). In areas of crossing satellite orbits where the phase could be successfully unwrapped, formal uncertainty in the horizontal velocity components is 3-5 $\mathrm{m} \mathrm{a}^{-1}$. In addition to the formal uncertainties, an additional $\sim 3 \%$ uncertainty is introduced in the process of removing vertical displacements (Joughin and others, 2009). A third uncertainty component comes from systematic errors in the SAR baseline estimate used to convert image displacements and phase differences into velocity values. While every effort has been made to minimize these errors, for velocity estimates derived from image pairs with short temporal intervals, these errors can be on the order of $50 \mathrm{~m} \mathrm{a}^{-1}$, and are correlated over several tens to hundreds of kilometers (Joughin and others, 2010b). The uncertainties of the InSAR velocities presented in Section 3 are the sum of the formal uncertainty and 3\% uncertainty from removing vertical displacements. 


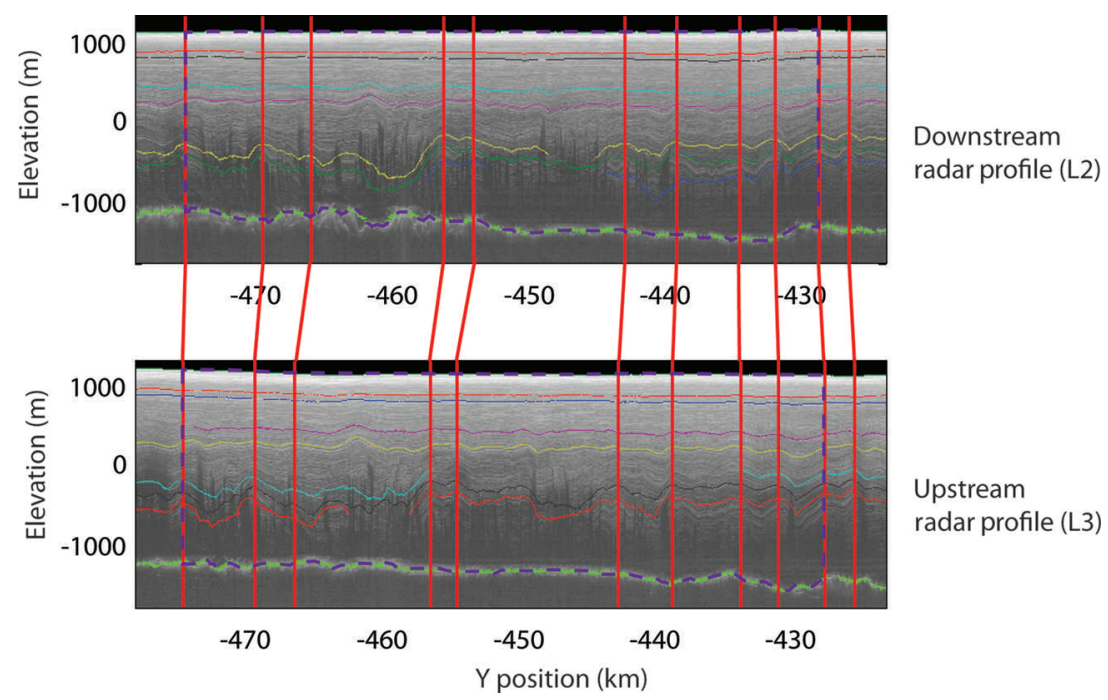

Fig. 2. Two radio-echograms with traced internal layers in different colors. Flowlines from matching distinct layer patterns between radio-echograms are shown by vertical red lines. Flux-gate areas of the outer flowlines used in the flux balance calculations are shown in dashed purple.

An InSAR velocity map is also available from Rignot and others (2011). The map uses the same 1996 data as Joughin and others (2009) but also incorporates data from 2007 and
2008 that cover portions of Thwaites Glacier. We primarily use the map of Joughin and others (2009) because it was developed for detailed investigations of Thwaites Glacier.

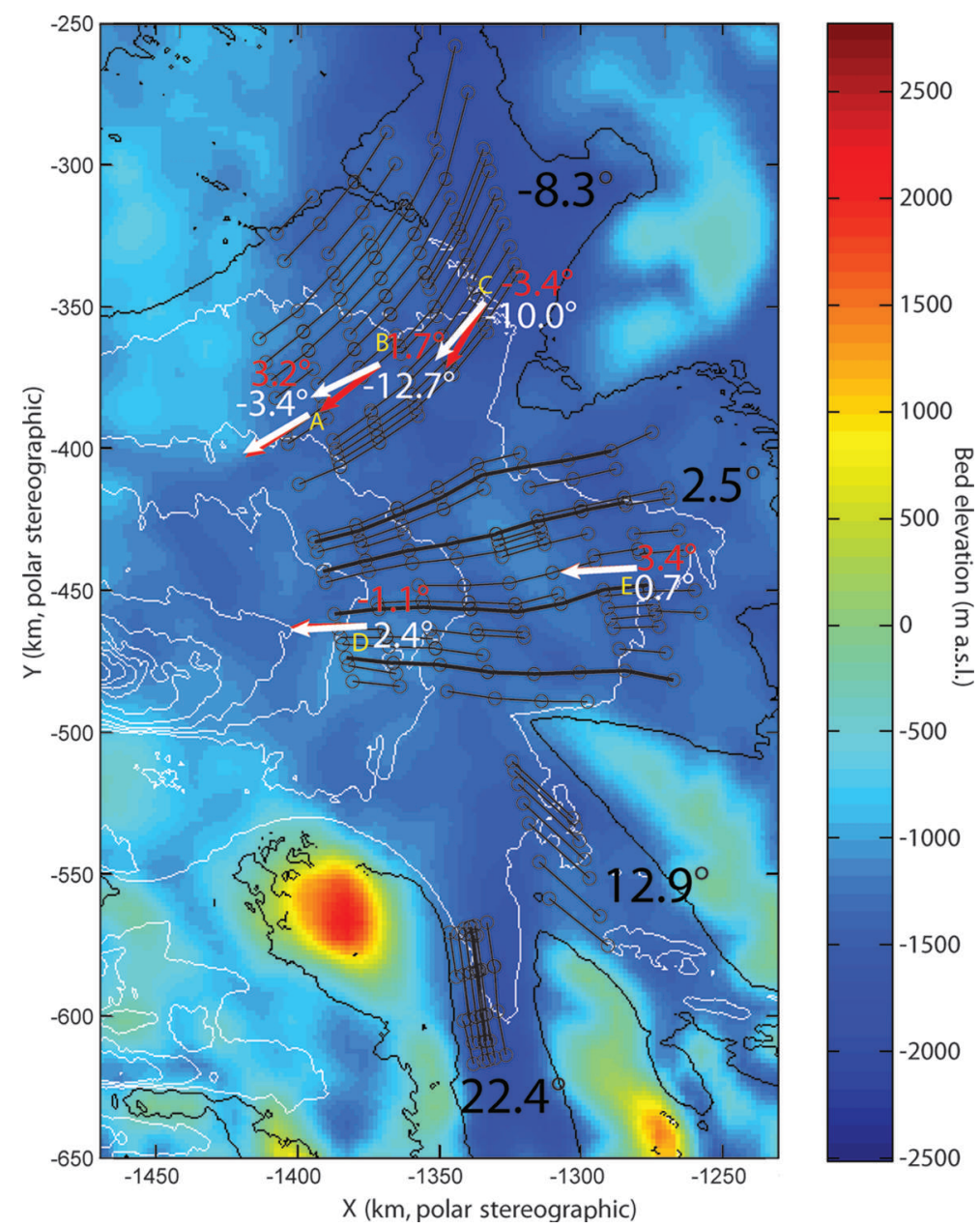

Fig. 3. Radar-detected flowlines shown with black circles connected by thin black lines. Thick black lines mark flowlines tracked for $110 \mathrm{~km}$, with the outside flowlines defining the flowband study area. Yellow letters are GPS station locations. White arrows are GPS velocities. Red arrows are InSAR velocities at GPS locations. Large black numbers are average radar-detected directions minus InSAR directions $\left(^{\circ}\right)$. Small white numbers are GPS directions minus InSAR directions. Small red numbers are GPS directions minus radar-detected directions. Background color is bedrock elevation. 
Table 1. Comparison of ice-flow directions

\begin{tabular}{|c|c|c|c|c|c|c|}
\hline Tributary & Station & GPS direction & Radar-detected direction & $\begin{array}{c}\text { InSAR direction } \\
\circ\end{array}$ & GPS minus radar-detected & GPS minus InSAR \\
\hline Eastern & $A$ & 236.2 & 233.0 & 239.6 & 3.2 & -3.4 \\
\hline Eastern & B & 231.6 & 229.8 & 244.2 & 1.7 & -12.7 \\
\hline Eastern & C & 210.1 & 213.5 & 220.1 & -3.4 & -10.0 \\
\hline Middle & D & 269.2 & 270.3 & 266.9 & -1.1 & 2.4 \\
\hline Middle & $E$ & 267.4 & 264.0 & 266.7 & 3.4 & 0.7 \\
\hline
\end{tabular}

We discuss differences between Rignot and others' (2011) and Joughin and others' (2009) velocities in Section 3.3.

\subsection{GPS measurements}

Dual-frequency GPS units (Trimble 5700, R7, NetRS receivers with Trimble Zephyr geodetic antennas) were installed for $\sim 4$ week durations during the 2007/08 Antarctic summer along the two main trunks of Thwaites Glacier and on the surrounding slow-moving, flanking ice. GPS antennas were mounted on rigid metal poles that extended $\sim 1-2 \mathrm{~m}$ across the ice surface. Our processing strategy generally follows that outlined by King (2004) for glaciological applications. GPS stations on streaming ice were processed kinematically relative to a local base station using differential carrier-phase positioning, with epoch-by-epoch zenith tropospheric delay estimation as implemented in the Track software (Chen, 1998) with very loose constraints on rover site motion. Daily solutions for the local base station on slow-moving ice near Mount Takahe were calculated using differential carrierphase positioning as implemented in GAMIT/GLOBK. Antenna heights were updated daily assuming a linear trend between measured antenna heights at the beginning and end of the field season. Horizontal velocities were extracted from linear fits for the entire field seasons using iteratively reweighted least squares with bi-square weighting after data were transformed into a polar stereographic projection (central meridian is $0^{\circ}$ and latitude of true scale is $-71^{\circ} \mathrm{S}$ ). Although formal uncertainties (defined as two standard deviations from the best fit) were very small $\left(\sim 0.001 \mathrm{~m} \mathrm{a}^{-1}\right)$, we conservatively estimate horizontal velocity uncertainties at $\sim 0.2 \mathrm{~m} \mathrm{a}^{-1}$ based on values of residuals from the best-fit line to account for errors associated with antenna height uncertainty, firn compaction and advection.

\subsection{Accumulation rate}

Measurements of accumulation in the interior of Thwaites Glacier are sparse. Kaspari and others (2004) report measurements from eight firn/ice cores in central West Antarctica. The one core in the Thwaites Glacier catchment indicated average accumulation of $0.48 \mathrm{~m} \mathrm{a}^{-1}$ (reported accumulation rates are in ice equivalent) over the period 1922-91. Several studies have used these data to help constrain regional climate models (e.g. Arthern and others, 2006; Monaghan and others 2006; Van de Berg and others, 2006); estimates of accumulation in the Thwaites catchment range from 0.4 to $0.65 \mathrm{~m} \mathrm{a}^{-1}$. Recent work using a combination of radar-detected shallow layers and firn cores found an average accumulation rate of $0.46 \mathrm{~m} \mathrm{a}^{-1}$ for the entire Thwaites catchment (Medley and others, 2013). For our study area, the accumulation rate for each segment was calculated from Medley and others' (2013) accumulation map and had an average of $0.54 \mathrm{~m} \mathrm{a}^{-1}$. The study area was well covered by radar lines, yielding an uncertainty in the accumulation rate for each segment of $0.05 \mathrm{~m} \mathrm{a}^{-1}$.

\section{RESULTS}

\subsection{Ice-flow direction}

Ice-flow directions defined by radar-detected features and by InSAR differed by an average of $2.5^{\circ}$ in the middle tributary but substantially more in the other tributaries. Figure 3 shows the average direction difference for each tributary. The InSAR directions are rotated eastward (towards the top) by an average of $8.3^{\circ}$ in the eastern tributary relative to the radar-defined directions. The disagreement is even larger for the two western tributaries although the number of measurements of radar-defined flowlines is smaller. The InSAR directions are rotated westward by an average of $12.9^{\circ}$ in the southwestern tributary and $22.4^{\circ}$ in the western tributary.

Differences between the ice-flow direction inferred by tracking internal radar features and the InSAR directions could indicate a change in flow pattern over the past few centuries because the radar-detected directions indicate directions for the past few centuries while the InSAR directions are a modern snapshot. However, the differences might also be due to inaccuracies of one of the methods. To examine potential inaccuracies, we compare the flow directions to those measured at five GPS stations. Stations $\mathrm{A}-\mathrm{C}$ are located in the eastern tributary, and $\mathrm{D}$ and $\mathrm{E}$ are in the middle tributary. GPS units were not deployed in the southwestern and western tributaries, where differences are largest. The radar-detected and GPS directions differed by up to $3.4^{\circ}$, which is within the combined uncertainty; the differences are not biased in one direction (Table 1). The maximum difference between InSAR and GPS directions is $12.7^{\circ}$. The agreement is good in the middle tributary, but consistently rotated eastward in the eastern tributary.

The agreement between radar-detected and GPS directions in the eastern tributary suggests that the InSAR directions are incorrect. The large differences between the radar-detected and InSAR directions in the western and southwestern tributaries are also likely caused by incorrect InSAR directions. Close inspection shows that radar-detected directions follow the bedrock trough and the direction of increasing ice velocity magnitude. In contrast, InSAR velocity vectors are oriented such that an ice particle starts in the center of a tributary and travels across the margin into slower-moving ice.

\subsection{Flux imbalance and uncertainty}

Flowbands can be tracked between six to eight radar lines in both the eastern and middle tributaries. This is a distance of 
Table 2. Values at flux gates

\begin{tabular}{lccccccc}
\hline Radar line & $\begin{array}{c}\text { Flux } \\
\mathrm{km}^{3}\end{array}$ & $\begin{array}{c}\text { Depth } \\
\mathrm{m}\end{array}$ & $\begin{array}{c}\text { Width } \\
\mathrm{m}\end{array}$ & $\begin{array}{c}\text { Velocity } \\
\mathrm{m} \mathrm{a}^{-1}\end{array}$ & $\begin{array}{c}\text { Depth flux uncertainty } \\
\mathrm{km}^{3}\end{array}$ & $\begin{array}{c}\text { Width flux uncertainty } \\
\mathrm{km}^{3}\end{array}$ & $\begin{array}{c}\text { Velocity flux uncertainty } \\
\mathrm{km}^{3}\end{array}$ \\
\hline L1 & $30.0 \pm 2.4$ & $2313 \pm 5$ & $42263 \pm 600$ & $304 \pm 25$ & 0.1 & 0.4 & 2.4 \\
L2 & $29.4 \pm 1.3$ & $2409 \pm 5$ & $47993 \pm 600$ & $250 \pm 11$ & 0.1 & 0.4 & 1.3 \\
L3 & $29.9 \pm 1.4$ & $2470 \pm 5$ & $54884 \pm 600$ & $215 \pm 10$ & 0.1 & 0.3 & 1.3 \\
L4 & $28.7 \pm 1.5$ & $2523 \pm 5$ & $63620 \pm 600$ & $174 \pm 10$ & 0.1 & 0.3 \\
L5 & $26.9 \pm 1.7$ & $2434 \pm 5$ & $72582 \pm 600$ & $150 \pm 10$ & 0.1 & 0.2 & 1.9 \\
L6 & $25.4 \pm 1.9$ & $2528 \pm 5$ & $74870 \pm 600$ & $134 \pm 10$ & 0.0 & 0.2 & 1.7 \\
L7 & $23.6 \pm 1.7$ & $2735 \pm 5$ & $76886 \pm 600$ & $112 \pm 8$ & 0.0 & 0.2 & 1.7 \\
L8 & $22.8 \pm 1.7$ & $2774 \pm 5$ & $83688 \pm 600$ & $96 \pm 7$ & 0.0 & & \\
\hline
\end{tabular}

$80-110 \mathrm{~km}$ and presents the opportunity to determine thinning rates from mass conservation. The large differences between the ice-flow directions determined by InSAR and those determined by radar and by GPS for the eastern tributary prevent a reliable flowband analysis. However, the agreement of all three datasets in the middle tributary suggests the InSAR velocities may be sufficiently accurate to allow the thinning rate to be determined.

Four flowlines were tracked through at least eight radar lines in the middle tributary. We focus on the large flowband defined by the outer two flowlines (Fig. 3) and calculate the flux gate area at the top and bottom of each flowband segment. The flux gate area is the cross-sectional area between two flowlines (Fig. 2). Assuming no ice flow across the sides of a flowband, from continuity the flux through the upstream gate equals the flux out the downstream gate plus any mass changes within the flowband:

$$
A_{\mathrm{dn}} u_{\mathrm{dn}}=A_{\mathrm{up}} u_{\mathrm{up}}+(\dot{b}-\dot{h}-\dot{m}) \mathrm{SA}
$$

where $A$ is the flux gate area, $u$ is the average velocity at the flux gate, $d n$ indicates the downstream gate, up indicates the upstream gate, $\dot{b}$ is the ice-equivalent accumulation rate, $\dot{h}$ is the rate of change in ice thickness (positive for thickening), $\dot{m}$ is the rate of basal melting and SA is the surface area of the flowband. The basal melt rate in the study was calculated by Joughin and others (2009), and the entire study region is melting at the bed. Most of the study area has a near-zero melt rate, with some radar lines averaging a few centimeters of melt per year. The basal melt rate is always less than the accumulation uncertainty, so we do not consider it in our calculations.

The flowband width does not accumulate uncertainty because the radar-detected features are identified independently at each radar profile. Uncertainty in the flux gate width is then the uncertainty in defining the features at each end, which we estimate to be a total of $600 \mathrm{~m}$ in width. The radar lines are not always perpendicular to the ice flow, so we convert the measured width to the width perpendicular to the ice flow by multiplying by the cosine of the difference between the direction of the radar line and the direction of the ice flow. Up to $11 \%$ of bed returns for a flux gate cannot be distinguished; the maximum distance between bed returns is $1 \mathrm{~km}$. Depths vary by up to $50 \mathrm{~m}$ over $1 \mathrm{~km}$ distances, but typically variations are less. We interpolate linearly between measured bed returns and estimate that the lack of returns results in $<5 \mathrm{~m}$ depth uncertainty. Uncertainty of the radar wave speed in ice largely cancels at the upstream and downstream gates, so we ignore this contribution.
The velocity at the flux gate is determined from the InSAR velocity map. The surface velocity is considered equal to the depth-averaged velocity, i.e. the ice moves entirely by sliding. Using a steady-state temperature profile with a surface temperature of $-20^{\circ} \mathrm{C}$, an accumulation rate of $0.5 \mathrm{~m} \mathrm{a}^{-1}$ and a basal temperature at the melting point, the contribution of internal deformation to the surface velocity is $\sim 5 \mathrm{~m} \mathrm{a}^{-1}$ in the study area. The depth-averaged velocity is $\sim 0.95$ of the surface velocity. This results in a possible overestimation of the depth-averaged velocity of $<1 \mathrm{ma}^{-1}$, which is much smaller than the InSAR uncertainty and is not considered here. Such an overestimation would have little impact on the flux balance calculations because each flux gate would be biased in the same direction.

The net flux, average depth, width and velocity at each gate are shown in Table 2, as well as the associated uncertainties. The total flux uncertainty is calculated assuming standard propagation of independent errors. The uncertainty for each flux gate is $5-10 \%$ of the total flux and is dominated by the velocity.

The net flux imbalance as well as the equivalent change in ice thickness averaged over the surface area is shown in Table 3 for each segment. A positive value indicates more mass is entering the segment, which results in thickening; a negative value indicates thinning. The uncertainty for any segment is often an order of magnitude larger than the calculated thickness change. This arises for short segments $(15.6 \mathrm{~km})$ because the flux difference is small and the velocity uncertainties at both flux gates dominate the estimate.

The full $110 \mathrm{~km}$ flowband allows a more robust estimate of average thinning and is also shown in Table 2. The average thinning rate is $0.47 \pm 0.42 \mathrm{ma}^{-1}$. L1 has a large velocity uncertainty, so calculating the thinning from L2-L8 yields nearly the same thinning rate of $0.49 \mathrm{ma}^{-1}$ but reduces the uncertainty to $0.34 \mathrm{~m} \mathrm{a}^{-1}$.

\subsection{Additional velocity uncertainty}

Uncertainty in the flux analysis is dominated by the velocity uncertainty. Thus far, we have assumed that the formal and slope-dependent uncertainties sufficiently characterized the velocity uncertainty, as in the Ross Drainage where the InSAR velocities were compared with ground-based measurements (Joughin and others, 2002). However, Thwaites Glacier is a difficult area for InSAR measurements. High accumulation rates and low radar reflectivity lead to poor coherence and rapid temporal decorrelation between images. As a result, in many parts of the glacier, only a few short-repeat image pairs from the European Remote-sensing 
Table 3. Flowband ice thickness change and uncertainty

\begin{tabular}{|c|c|c|c|c|c|c|c|c|c|c|}
\hline \multirow[t]{2}{*}{ Flowband } & \multirow{2}{*}{$\begin{array}{c}\text { Surface area } \\
\mathrm{km}^{2}\end{array}$} & \multirow{2}{*}{$\begin{array}{c}\text { Accumulation } \\
\mathrm{m} \mathrm{a}^{-1}\end{array}$} & \multirow{2}{*}{$\begin{array}{c}\text { Surface flux } \\
\mathrm{km}^{3}\end{array}$} & \multirow{2}{*}{$\begin{array}{c}\text { Net flux } \\
\mathrm{km}^{3}\end{array}$} & \multirow{2}{*}{$\begin{array}{c}\text { Thickness } \\
\text { change } \\
\mathrm{m} \mathrm{a}^{-1}\end{array}$} & \multirow{2}{*}{$\begin{array}{c}\text { Thickness } \\
\text { change } \\
\text { uncertainty } \\
\text { from depth } \\
\mathrm{ma}^{-1}\end{array}$} & \multirow{2}{*}{$\begin{array}{c}\text { Thickness } \\
\text { change } \\
\text { uncertainty } \\
\text { from width } \\
\mathrm{ma}^{-1}\end{array}$} & \multirow{2}{*}{$\begin{array}{c}\text { Thickness } \\
\text { change } \\
\text { uncertainty } \\
\text { from velocity } \\
\mathrm{ma}^{-1}\end{array}$} & \multirow{2}{*}{$\begin{array}{c}\text { Thickness } \\
\text { change } \\
\text { uncertainty } \\
\text { from } \\
\text { accumulation } \\
\mathrm{m} \mathrm{a}^{-1}\end{array}$} & \multirow{2}{*}{$\begin{array}{c}\text { Total } \\
\text { thickness } \\
\text { change } \\
\text { uncertainty } \\
\mathrm{m} \mathrm{a}^{-1}\end{array}$} \\
\hline & & & & & & & & & & \\
\hline L2-L3 & 806 & 0.57 & 0.44 & $0.9 \pm 2.4$ & 1.16 & 0.10 & 0.60 & 2.27 & 0.05 & 2.35 \\
\hline L3-L4 & 923 & 0.55 & 0.51 & $-0.7 \pm 2.2$ & -0.73 & 0.09 & 0.45 & 2.18 & 0.05 & 2.23 \\
\hline L4-L5 & 1064 & 0.53 & 0.59 & $-1.2 \pm 2.2$ & -1.09 & 0.07 & 0.32 & 2.14 & 0.05 & 2.17 \\
\hline L5-L6 & 1154 & 0.53 & 0.63 & $-0.9 \pm 2.2$ & -0.82 & 0.06 & 0.26 & 2.20 & 0.05 & 2.22 \\
\hline L6-L7 & 1185 & 0.54 & 0.65 & $-1.1 \pm 2.1$ & -0.93 & 0.06 & 0.23 & 2.13 & 0.05 & 2.15 \\
\hline L7-L8 & 1257 & 0.53 & 0.69 & $-0.1 \pm 1.9$ & -0.09 & 0.05 & 0.19 & 1.87 & 0.05 & 1.88 \\
\hline L1-L8 & 7093 & 0.54 & 3.90 & -3.3 & -0.47 & 0.01 & 0.06 & 0.41 & 0.05 & 0.42 \\
\hline L2-L8 GPS & 6389 & 0.54 & 3.51 & -2.2 & -0.36 & 0.01 & 0.06 & $0.01^{*}$ & 0.05 & $0.08^{*}$ \\
\hline
\end{tabular}

*The velocity uncertainty is from the GPS uncertainty only and does not include uncertainty due to spatial variation.

Satellite (ERS) are available. These estimates have larger errors and biases than those based on the 23 or 38 day pairs available elsewhere.

The InSAR and GPS velocities are compared in Table 4. In the eastern tributary, where the flow directions do not agree, the InSAR velocities exceed the GPS velocities by $16 \%$ at site $A$ and $13 \%$ at site $B$, which is more than the formal and slope-dependent uncertainty and indicates that there is additional uncertainty from the short repeat interval. In the middle tributary, the InSAR velocity is $5 \%$ greater at site $\mathrm{D}$ and slightly outside of the uncertainty; at site $\mathrm{E}$, they agree within the uncertainty. The comparison suggests that uncertainty in the velocity magnitude is reasonable in places where the direction is accurate, and inaccurate directions are an indication that the magnitude may be off as well.

At four of the five GPS locations, the InSAR velocity is greater than the GPS velocity. It is unlikely that the difference is caused by the different times at which the velocities were measured; InSAR velocities are from 1996 and GPS velocities are from austral summer 2007/08. Thwaites Glacier is most likely accelerating in response to recent terminus changes, so the GPS velocities would be expected to be greater than the InSAR velocities.

We also compared the GPS velocities with the velocity map of Rignot and others (2011). Rignot and others use a combination of the 1996 ERS-1 and -2 satellite passes (from which Joughin and others' (2009) velocities were calculated) as well as the 2007/08 Phased Array-type L-band SAR
(PALSAR) data, which do not cover the entire region. InSAR velocity directions from Rignot and others (2011) agree well with those calculated using GPS in the eastern tributary (difference is $<2.5^{\circ}$; Table 1); however, the directions differ by $9.5^{\circ}$ and $5.3^{\circ}$ in the middle tributary. This is opposite to those from Joughin and others (2009), which agree well in the middle tributary but not the eastern tributary. Gaps in Rignot and others' (2011) velocity map prevent comparisons with the radar-detected directions in the western and southwestern tributaries.

Rignot and others' (2011) velocities are less than the GPS velocities at four of the five GPS locations, and the differences exceed the stated velocity uncertainties at three of the five sites. Velocity differences often exceed the stated uncertainties by more than an order of magnitude. At site D, Rignot and others (2011) give a $1 \mathrm{~m} \mathrm{a}^{-1}$ velocity uncertainty, yet the GPS velocity is $28 \mathrm{~m} \mathrm{a}^{-1}(12 \%)$ faster; at site $\mathrm{E}$, the GPS velocity is $15 \mathrm{~m} \mathrm{a}^{-1}$ (14\%) faster, although the stated uncertainty is $1 \mathrm{~m} \mathrm{a}^{-1}$. Agreement between Rignot and others' (2011) velocities and GPS velocities is better in the eastern tributary; the difference exceeds the uncertainty at only one of the three sites. This suggests that the velocity magnitudes are more accurate where the directions agree, as observed with Joughin and others' (2009) velocities.

The large differences between the GPS and both InSAR velocities (and even larger differences between the two InSAR maps) suggest the uncertainties that accompany the InSAR data are too small and need to include uncertainty associated with short repeat intervals. Hence the estimated

Table 4. Velocity comparison

\begin{tabular}{|c|c|c|c|c|c|c|c|c|}
\hline Tributary & Station & $\begin{array}{l}\text { GPS velocity } \\
\mathrm{m} \mathrm{a}^{-1}\end{array}$ & $\begin{array}{c}\text { Joughin } \\
\text { InSAR velocity } \\
\mathrm{m} \mathrm{a}^{-1}\end{array}$ & $\begin{array}{c}\text { Rignot } \\
\text { InSAR velocity } \\
\mathrm{m} \mathrm{a}^{-1}\end{array}$ & $\begin{array}{c}\text { GPS - Joughin } \\
\text { InSAR } \\
\mathrm{m} \mathrm{a}^{-1}\end{array}$ & $\begin{array}{c}\text { Joughin InSAR } \\
\text { uncertainty } \\
\mathrm{m} \mathrm{a}^{-1}\end{array}$ & $\begin{array}{c}\text { GPS - Rignot } \\
\text { InSAR } \\
\mathrm{m} \mathrm{a}^{-1}\end{array}$ & $\begin{array}{c}\text { Rignot InSAR } \\
\text { uncertainty } \\
\mathrm{m} \mathrm{a}^{-1}\end{array}$ \\
\hline Eastern & A & 140.6 & 164.4 & 128.8 & 23.8 & 7.7 & -11.8 & 3.0 \\
\hline Eastern & B & 111.0 & 125.5 & 108.9 & 14.5 & 7.8 & -2.1 & 3.2 \\
\hline Eastern & C & 108.1 & 99.8 & 108.4 & -8.3 & 15.9 & 0.3 & 3.0 \\
\hline Middle & $\mathrm{D}$ & 249.3 & 263.5 & 221.1 & 14.2 & 12.0 & -28.2 & 1.0 \\
\hline Middle & $\mathrm{E}$ & 113.2 & 116.4 & 97.8 & 3.2 & 7.9 & -15.4 & 1.0 \\
\hline
\end{tabular}


uncertainty of the flux analysis presented above is likely higher than stated, which reduces the confidence in the thinning estimates.

GPS velocities provide the necessary precision but lack spatial coverage. If the velocities at the L2 and L8 gates (from Joughin and others, 2009) are scaled to the GPS velocities, the inferred thinning is reduced to $0.36 \mathrm{ma}^{-1}$, in closer agreement with the altimetry methods. The uncertainty is difficult to estimate because while the GPS velocities have an uncertainty of $0.2 \mathrm{ma}^{-1}$, a constant scaling of all velocities along the flux gate is likely too simplistic. If only the GPS velocity uncertainty is used, the total uncertainty is $0.08 \mathrm{~m} \mathrm{a}^{-1}$, which is similar to the precision of the laser altimetry techniques; the uncertainty in accumulation then dominates the overall uncertainty estimate. Multiple GPS measurements at the flux gates would be necessary to reduce the velocity uncertainty.

\section{CONCLUSIONS}

Flowlines can be effectively determined using radardetected features in the interior of Thwaites Glacier where other means of identifying flow directions (e.g. flow stripes and crevasses at shear margins) are not possible. Comparisons of GPS and radar-detected flow directions with InSAR directions indicate that InSAR velocities alone are not sufficient to define flowlines and flowbands. The agreement of the GPS and radar-detected flowlines also reveals that flow directions of Thwaites Glacier tributaries have not changed significantly over the past few hundred years.

A flux analysis in the middle tributary where the InSAR velocity directions agree well with the GPS and radardetected directions indicates thinning of $0.49 \mathrm{~m} \mathrm{a}^{-1}$, but with a large uncertainty of $0.34 \mathrm{~m} \mathrm{a}^{-1}$. Further, InSAR velocities often differ from GPS velocities by more than InSAR uncertainties, indicating that the flux analysis uncertainty is too low. The large uncertainty of the flux balance analysis prevents inference of thinning estimates with similar precision to satellite altimetry, which indicates thinning of $0.10-0.15 \mathrm{~m} \mathrm{a}^{-1}$ with uncertainties of $\sim 0.1 \mathrm{~m} \mathrm{a}^{-1}$ (Zwally and others, 2005; Helsen and others, 2008; Pritchard and others, 2009). InSAR velocities provide a good overview of the velocity structure of Thwaites Glacier and are sufficient for many glaciological investigations (Joughin and others, 2009; Rignot and others, 2011), but they are not sufficiently accurate for flux analyses in upstream tributaries.

\section{ACKNOWLEDGEMENTS}

We thank Brooke Medley and Joe MacGregor for many discussions about Thwaites Glacier. We also thank the US National Science Foundation for supporting this research with grants ANT-0739372 to H.C. and 0632198 to S.A. We also appreciate the efforts of editors Dorthe Dahl-Jensen and David Braaten.

\section{REFERENCES}

Arthern RJ, Winebrenner DP and Vaughan DG (2006) Antarctic snow accumulation mapped using polarization of $4.3-\mathrm{cm}$ wavelength microwave emission. J. Geophys. Res., 111(D6), D06107 (doi: 10.1029/2004JD005667)

Blankenship D and Young D (2012) AGASEA ice thickness profile data from the Amundsen Sea Embayment, Antarctica. National
Snow and Ice Data Center, Boulder, CO. Digital media: http://nsidc.org/data/nsidc-0517

Chen G (1998) GPS kinematic positioning for the airborne laser altimetry at Long Valley, California. (PhD thesis, Massachusetts Institute of Technology)

Conway H, Catania G and Fudge TJ (2010) Ice flow history of the Thwaites Glacier, West Antarctica. National Snow and Ice Data Center, Boulder, CO. Digital media: http://nsidc.org/data/ nsidc-0463

Fahnestock MA, Scambos TA, Bindschadler RA and Kvaran G (2000) A millennium of variable ice flow recorded by the Ross Ice Shelf, Antarctica. J. Glaciol., 46(155), 652-664 (doi: 10.3189/ 172756500781832693)

Helsen MM and 7 others (2008) Elevation changes in Antarctica mainly determined by accumulation variability. Science, 320(5883), 1626-1629 (doi: 10.1126/science.1153894)

Holt JW and 8 others (2006) New boundary conditions for the West Antarctic Ice Sheet: subglacial topography of the Thwaites and Smith glacier catchments. Geophys. Res. Lett., 33(9), L09502 (doi: 10.1029/2005GL025561)

Joughin I, Tulaczyk S, Bindschadler RA and Price S (2002) Changes in West Antarctic ice stream velocities: observation and analysis. J. Geophys. Res., 107(B11), 2289 (doi: 10.1029/ 2001JB001029)

Joughin I and 6 others (2009) Basal conditions for Pine Island and Thwaites Glaciers, West Antarctica, determined using satellite and airborne data. J. Glaciol., 55(190), 245-257 (doi: 10.3189/ 002214309788608705)

Joughin I, Smith BE and Holland DM (2010a) Sensitivity of 21st century sea level to ocean-induced thinning of Pine Island Glacier, Antarctica. Geophys. Res. Lett., 37(20), L20502 (doi: 10.1029/2010GL044819)

Joughin I, Smith BE, Howat IM, Scambos T and Moon T (2010b) Greenland flow variability from ice-sheet-wide velocity mapping. J. Glaciol., 56(197), 415-430 (doi: 10.3189/ $002214310792447734)$

Kaspari S and 6 others (2004) Climate variability in West Antarctica derived from annual accumulation-rate records from ITASE firn/ice cores. Ann. Glaciol., 39, 585-594 (doi: 10.3189/ $172756404781814447)$

King M (2004) Rigorous GPS data-processing strategies for glaciological applications. J. Glaciol., 50(171), 601-607 (doi: 10.3189/172756504781829747)

MacGregor J, Catania GA, Markowski MS and Andrews AG (2012) Widespread rifting and retreat of ice-shelf margins in the eastern Amundsen Sea Embayment between 1972 and 2011. J. Glaciol., 58(209), 458-466 (doi: 10.3189/2012JoG11J262)

MacGregor J and 7 others (2013) Weak bed control of the eastern shear margin of Thwaites Glacier, West Antarctica. J. Glaciol., 59(217), 900-912

Medley B and 12 others (2013) Airborne-radar and ice-core observations of annual snow accumulation over Thwaites Glacier, West Antarctica confirm the spatiotemporal variability of global and regional atmospheric models. Geophys. Res. Lett., 40(14), 3649-3654 (doi: 10.1002/grl.50706)

Monaghan AJ, Bromwich DH and Wang S-H (2006) Recent trends in Antarctic snow accumulation from Polar MM5 simulations. Philos. Trans. R. Soc. London, Ser. A, 364(1844), 1683-1708 (doi: 10.1098/rsta.2006.1795)

$\mathrm{Ng} \mathrm{F}$ and Conway H (2004) Fast-flow signature in the stagnated Kamb Ice Stream, West Antarctica. Geology, 32(6), 481-484 (doi: 10.1130/G20317.1)

Payne AJ, Vieli A, Shepherd A, Wingham DJ and Rignot E (2004) Recent dramatic thinning of largest West Antarctic ice stream triggered by oceans. Geophys. Res. Lett., 31(23), L23401 (doi: 10.1029/2004GLO21284)

Peters ME, Blankenship DD and Morse (2005) Analysis techniques for coherent airborne radar sounding: applications to West Antarctic ice streams. J. Geophys. Res., 110(B6), B06303 (10.1029/2004JB003222) 
Peters ME, Blankenship DD, Carter SP, Kempf SD, Young DA and Holt JW (2007) Along-track focusing of airborne radar sounding data from West Antarctica for improving basal reflection analysis and layer detection. IEEE Trans. Geosci. Remote Sens., 45(9), 2725-2736 (doi: 10.1109/TGRS.2007.897416)

Pritchard HD, Arthern RJ, Vaughan DG and Edwards LA (2009) Extensive dynamic thinning on the margins of the Greenland and Antarctic ice sheets. Nature, 461(7266), 971-975 (doi: 10.1038/nature08471)

Pritchard HD, Ligtenberg SRM, Fricker HA, Vaughan DG, Van den Broeke MR and Padman L (2012) Antarctic ice-sheet loss driven by basal melting of ice shelves. Nature, 484(7395), 502-505 (doi: 10.1038/nature10968)

Rignot E (2008) Changes in West Antarctic ice stream dynamics observed with ALOS PALSAR data. Geophys. Res. Lett., 35(12), L12505 (doi: 10.1029/2008GL033365)

Rignot E, Vaughan DG, Schmeltz M, Dupont T and MacAyeal D (2002) Acceleration of Pine Island and Thwaites Glaciers, West Antarctica. Ann. Glaciol., 34, 189-194 (doi: 10.3189/ 172756402781817950)

Rignot E and 6 others (2008) Recent Antarctic ice mass loss from radar interferometry and regional climate modelling. Nature Geosci., 1(2), 106-110 (doi: 10.1038/ngeo102)
Rignot E, Mouginot J and Scheuchl B (2011) Ice flow of the Antarctic Ice Sheet. Science, 333(6048), 1427-1430 (doi: 10.1126/science.1208336)

Shabtaie S, Bentley CR, Bindschadler RA and MacAyeal DR (1988) Mass-balance studies of Ice Streams A, B, and C, West Antarctica, and possible surging behavior of Ice Stream B. Ann. Glaciol., 11, 137-149

Shepherd A and 46 others (2012) A reconciled estimate of ice-sheet mass balance. Science, 338(6111), 1183-1189 (doi: 10.1126/ science.1228102)

Van de Berg WJ, Van den Broeke MR, Reijmer $\mathrm{CH}$ and Van Meijgaard E (2006) Reassessment of the Antarctic surface mass balance using calibrated output of a regional atmospheric climate model. J. Geophys. Res., 111(D11), D11104 (doi: 10.1029/2005JD006495)

Vaughan, DG and 9 others (2006) New boundary conditions for the West Antarctic ice sheet: subglacial topography beneath Pine Island Glacier. Geophys. Res. Lett., 33(9), L09501 (10.1029/ 2005GL025588)

Zwally HJ and 7 others (2005) Mass changes of the Greenland and Antarctic ice sheets and shelves and contributions to sea-level rise: 1992-2002. J. Glaciol., 51(175), 509-527 (doi: 10.3189/ $172756505781829007)$ 